\title{
Correction to: Additive-free alkoxide-water-alcohol solutions as precursors for crystalline titania thin films
}

\author{
Shinnosuke Yamazaki ${ }^{1} \cdot$ Hiroaki Uchiyama ${ }^{1} \cdot$ Hiromitsu Kozuka ${ }^{1}$
}

Published online: 2 August 2018

(c) Springer Science+Business Media, LLC, part of Springer Nature 2018

Correction to: Journal of Sol-Gel Science and Technology https://doi.org/10.1007/s10971-018-4715-x

The original version of this article unfortunately contained a typo in the Fig. 3 label. The age range in figure label is submitted and published as 1-3 days, instead it should be 1-30 days. The corrected figure is given below. The original article has been corrected.

The original article can be found online at https://doi.org/10.1007/ s10971-018-4715-x.

Hiromitsu Kozuka

kozuka@kansai-u.ac.jp

1 Department of Chemistry and Materials Engineering, Kansai University, 3-3-35 Yamate-cho, Suita 564-8680, Japan 

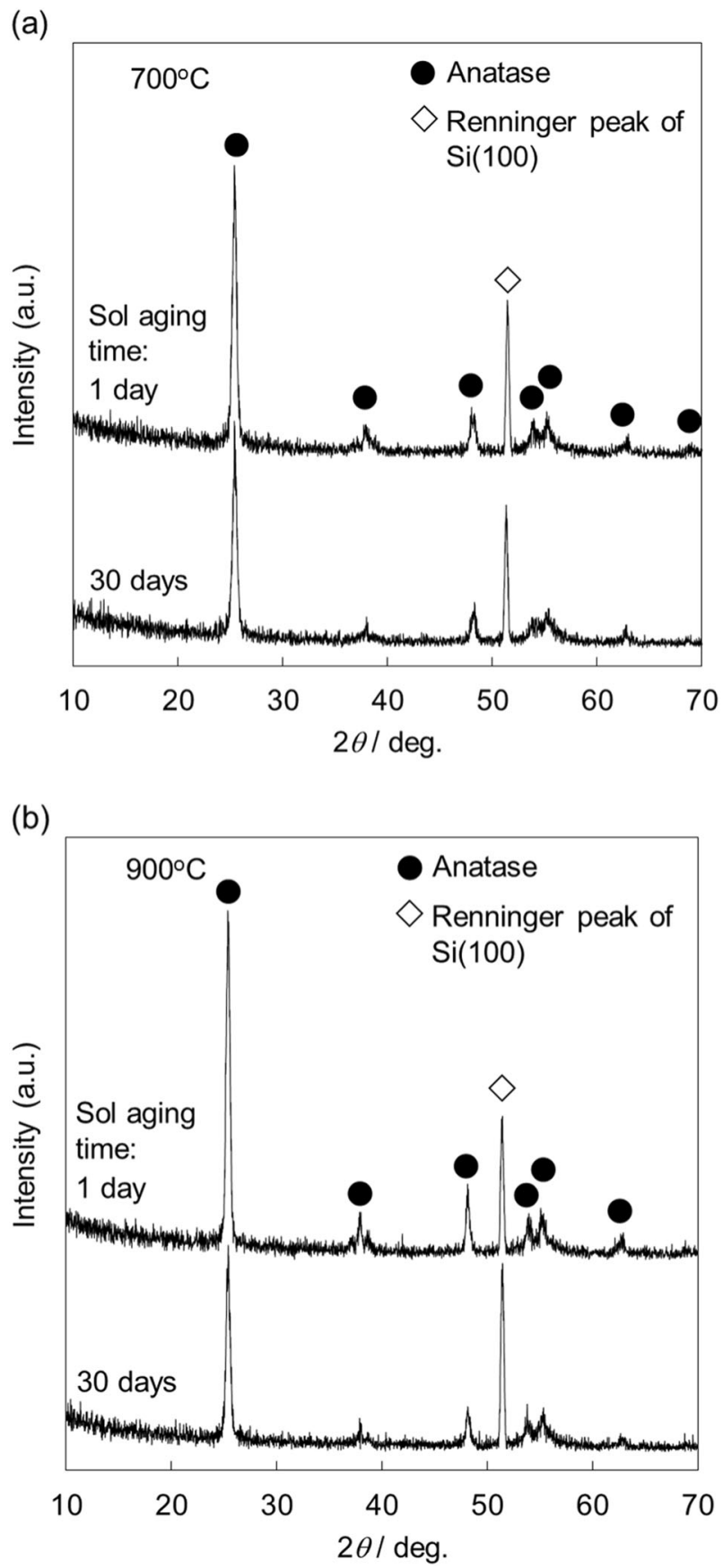

Fig. 3 XRD patterns of the titania thin films prepared from Solution ME25-W1 aged for 1 and 30 days. The gel films were fired at a 700 and b $900{ }^{\circ} \mathrm{C}$ 